\title{
EM BUSCA DE REFERÊNCIAS CONCEITUAIS PARA ENTENDER A AVALIAÇÃO DE IMPACTO
}

\author{
Maria da Glória Serra Pinto de Alencar \\ Universidade Federal do Maranhão (UFMA)
}

\section{EM BUSCA DE REFERÊNCIAS CONCEITUAIS PARA ENTENDER A AVALIAÇÃO DE IMPACTO}

Resumo: Este artigo traz reflexões teóricas acerca da avaliação de impacto social. Enfatiza as abordagens de Silva (2008), Lima (2008; 2009), Aguilar e Ander-Egg (1994), dentre outros, sobre as diversas concepções de avaliação como um movimento no processo das políticas públicas. Apresenta diversas tipologias e modelos de avaliação, centrando a discussão na avaliação de impacto social. Aborda o impacto social como uma função ético-filosófica, ligada a uma determinada concepção de mundo que resgata os valores do ser humano, seu desenvolvimento, sua criatividade, no contexto de um processo de aprendizagem guiado e direcionado para formas de convivência superior. Conclui que a avaliação de impacto social deve ser entendida antes de tudo como uma atitude diante da vida e das coisas e como um instrumento para construir o futuro.

Palavras-chave: Avaliação de impacto, impacto social, políticas públicas.

\section{SEARCHING FOR CONCEPTUAL REFERENCE TO UNDERSTAND THE IMPACT EVALUATION}

Abstract: This article brings theoretical reflections on the social impact evaluation. It emphasizes the approaches of Silva (2008), Lima (2008, 2009), Aguilar and Ander-Egg (1994), among others, about different conceptions of evaluation as a movement in the process of public policies. It presents various types and models of evaluation, focusing the discussion on the social impact evaluation. Addresses the social impact as an ethical and philosophical function, linked to a particular conception of the world which rescue the values of human beings, their development, their creativity in the context of a learning process, guided and directed to better acquaintanceship ways. Concludes that the social impact assessment should be understood primarily as an attitude toward life and things and as a tool to build the future.

Key words: Impact evaluation, social impact, policies. 


\section{INTRODUÇÃO}

Apesar de reconhecer o caráter incipiente da pesquisa e da prática avaliativa no Brasil (FARIA, 2005, p. 98), existe, na atualidade, uma vasta e diversificada literatura sobre a questão da avaliação. Entretanto, no que se refere à avaliação de impacto social dentro de uma visão de totalidade social, como a que se refere Muñiz (1997) "o impacto social está indubitavelmente ligado a uma concepção de totalidade social", tem-se uma literatura mais restrita, daí porque se adotam, para esta reflexão específica, basicamente as ideias da referida autora.

O objetivo deste trabalho consiste, então, em realizar uma revisão da literatura especializada e recente sobre avaliação de políticas públicas com ênfase à avaliação de impacto, notadamente, o impacto social.

Para tal, inicialmente discorre-se que a definição de avaliação faz parte de um dos movimentos do processo das políticas públicas, enfatizando principalmente as abordagens de Silva (2008), Lima (2008; 2009), Aguilar e AnderEgg (1994), dentre outros, no que se refere às diversas, mas nem por isso diferenciadas (talvez complementares), concepções sobre avaliação.

Em seguida, apresentam-se as diferentes tipologias e modelos de avaliação, numa tentativa de situar os aspectos conceituais e metodológicos da avaliação de impacto.

Finalmente, assim, introduzimos a reflexão sobre este modelo de avaliação, tomandoemprestada a concepção de vários autores, enfatizando com maior detalhe a abordagem de Muñiz (1997) sobre, especificamente, a avaliação de impacto social.

\section{O PROCESSO DAS POLÍTICAS PÚBLICAS E A DEFINIÇÃO DE AVALIAÇÃO}

São inúmeras as abordagens conceituais sobre as políticas públicas. De acordo com Sousa (2006, p. 24), "[...] não existe uma única, nem melhor, definição sobre o que seja política pública." Entretanto, existe consenso em um aspecto: as políticas públicas se constituem em um processo dinâmico e complexo onde intervêm muitos sujeitos que apresentam expectativas e interesses diversificados. Cada política é, portanto, o produto dessa complexa interação de pessoas e organizações, onde cada um desses sujeitos busca definir um problema para abordar ou uma realidade sobre a qual irá intervir. A política pública é considerada assim como uma forma de regulação ou intervenção na sociedade. (SILVA, 2008, p. 90).

Políticas públicas são também entendidas como o "Estado em ação" (GOBERT, MULLER, 1987 apud HOFLING, 2001); "[...] é o Estado implantando um projeto de governo, através de programas, de ações voltadas para setores específicos da sociedade." (HOFLING, 2001).
Entretanto,

Estadonãopodeserreduzidoàburocracia pública, aos organismos estatais que conceberiam e implementariam as políticas públicas. As políticas públicas são então compreendidas como as de responsabilidade do Estado, quanto à implementação e manutenção a partir de um processo de tomada de decisões que envolve órgãos públicos e diferentes organismos e agentes da sociedade relacionados à política implementada. Neste sentido, políticas públicas não podem ser reduzidas a políticas estatais. (HOFLING, 2001, grifo da autora).

Embora não seja objetivo deste trabalho discutir sobre o papel do Estado, cumpre salientar que

Estado moderno surge e se
desenvolve simultaneamente à
emergência e expansão do capitalismo
industrial, mantendo com este uma
relação de complementaridade e de
reciprocidade dialética que decorre do
fato de ambos serem partes integrantes
e indissociáveis de uma modalidade
particular de organização e controle
social regida pela ordem burguesa.
(LIMA, 2002, p. 129).

Ou seja, compartilha-se com Mészaros (2009) a concepção de Estado como estrutura totalizante de comando político do capital, capaz de garantir, ao mesmo tempo, a unidade do processo de acumulação e a legitimação da ordem burguesa.

Dessa forma, o Estado em conformidade com a própria dinâmica de desenvolvimento capitalista, assume historicamente configurações distintas, incorporando em sua organização essas duas lógicas, a acumulação e a legitimação, utilizandose dos instrumentos de coerção e de consenso (LIMA, 2002, p. 129). É assim, então, que o Estado Moderno toma as várias feições de Estado Liberal, Estado Social e, mais recentemente, incorporando - Processo de Reestruturação Capitalista Global, retoma os princípios liberais, assumindo a face do Neoliberalismo.

$\mathrm{Na}$ atualidade, com a recente crise (final de 2008, início de 2009), ficou ainda mais evidente para que serve o Estado e a serviço de quem ele é utilizado, pois para "salvar" o grande capital, aumentou seu déficit de forma significativa, desde que a crise começou.

Estamos diante de um movimento muito maior de reestruturação do capital que concentra o dito e fragmenta o social. Globalização só para o grande capital. Do trabalho e da pobreza, cada um que cuide do seu como puder. De preferência com Estados fortes para sustentar o 
sistema financeiro e falidos para cuidar do social. (SOARES apud MONTAÑO, 2007, p.13).

Como se sabe, em momentos de crise, as condições sociais tendem a piorar substancialmente. E mais angustiante ainda é verificar que tais iniquidades já haviam atingido um nível muito baixo antes da crise eclodir, exatamente porque os preceitos neoliberais já haviam acirrado ainda mais as desigualdades. Nesse sentido, vale destacar Mészaros (2009, p. 65),

A política é transformada em mero instrumento de grosseira manipulação completamente desprovido de qualquer plano global [...]A política fica condenada a seguir um padrão de movimento reativo tardio e de curto prazo, em resposta às crises desconcertantes que necessariamente irrompem, numa freqüência crescente.

Entende-se, então, que as políticas sociais se referem às ações que determinam o padrão de proteção social implementado pelo Estado, orientadas, a priori,

Para a redistribuição dos benefícios sociais visando, senão a eliminação, pelo menos a diminuição das desigualdades estruturais produzidas pelo desenvolvimento socioeconômico. As políticas sociais têm suas raízes nos movimentos populares do século XIX, voltadas aos conflitos surgidos entre capital e trabalho, no desenvolvimento das primeiras revoluções industriais. (HOFLING, 2001).

$\mathrm{Na}$ tentativa de chegar a um conceito de políticas públicas, Rua ([19--]), esclarece que

As políticas públicas (policies) [...] são [...] resultantes da atividade política (politics): compreendem o conjunto das decisões e ações relativas à alocação imperativa de valores.

Ou seja, além de valores, as políticas públicas incluem decisões, ritos, normas, procedimentos, recursos materiais, sujeitos sociais e se desenvolvem em movimentos com dinâmicas próprias, onde em cada um deles existem sujeitos, restrições e resultados que vão se relacionando entre si.

Isto significa que

As ações empreendidas pelo Estado não se implementam automaticamente, têm movimento, têm contradições e podem gerar resultados diferentes dos esperados. Especialmente por se voltar para e dizer respeito a grupos diferentes, o impacto das políticas públicas implementadas pelo Estado capitalista sofrem o efeito de interesses diferentes expressos nas relações sociais de poder. (HOFLING, 2001).

Por conseguinte, a política vista como um processo conjuga um conjunto de momentos, ou movimentos, não lineares, articulados e interdependentes e, às vezes, concomitantes (SILVA, 2008, p. 92). A maioria dos autores indica que estes movimentos são divididos em três fases, embora encontremos autores que ampliem estes estágios para mais de três momentos ou movimentos. Entretanto, na sua essência, a divisão em mais ou em menos fases não implica em conceitos diferenciados.

Tomando por base o que Sousa (2006, p. 29) denomina de ciclo ou processo da política pública, tem-se então: definição da agenda, identificação das alternativas, avaliação e seleção das opções implementação e avaliação.

No que se refere especificamente à avaliação, objeto de reflexão deste trabalho, esta se integra ao ciclo como atividade permanente que acompanha todas as fases da política pública, desde a identificação do problema da política até a análise das mudanças sociais advindas da intervenção pública.

Concebe-se também que a prática avaliativa, qualquer que seja o programa social, não pode ser neutra, visto que o sujeito é constitutivo do objeto e tem um papel ativo no processo de conhecimento e transformação.

Ademais,

Parte-se aqui do entendimento de que uma verdadeira avaliação implica em emitir um julgamento quanto ao mérito da política, mas não apenas isso. 'Uma boa e completa avaliação julga e explica. Mas julgar e, sobretudo, explicar é atributo da investigação científica'. (NEMES, 2001, p. 10). Portanto, é também papel da avaliação explicar as razões do êxito ou fracasso das ações implementadas. (LIMA, 2008, p. 229).

Muitas vezes confundida com monitoramento, que consiste em uma atividade gerencial interna realizada durante a execução do programa, isto é, no exame contínuo da execução de um programa, tendo como foco o cumprimento de metas de acordo com um cronograma preestabelecido, limitando-se a uma postura meramente corretiva e descritiva, a avaliação julga o mérito da política segundo critérios de eficiência, eficácia e efetividade, além de explicar as razões do êxito ou fracasso das ações implementadas (LIMA, 2009). 
A noção de sucesso ou fracasso de uma política depende obviamente dos propósitos dessa política e das razões que levaram o analista a avaliar tal política. Do lado dos propósitos das políticas, devemos considerar que as políticas públicas - as decisões governamentais - têm geralmente dois aspectos:

a) gerar um produto físico, tangível e mensurável [produção de bens e serviços públicos]; e

b) gerar um impacto, que, tanto pode ser físico, tangível e mensurável, quanto subjetivo, alterando atitudes, comportamentos e/ou opiniões [políticas voltadas a mudanças nas condições sociais]. [...]

Do lado das razões ou motivos que promovem a avaliação de políticas podemos identificar razões morais e razões instrumentais. (FIGUEIREDO, FIGUEIREDO, 1986, p. 109).

Entretanto, mais do que identificar os propósitos das políticas e os motivos ou razões que podem levar pessoas ou analistas a avaliar determinada política, o que nos interessa em questão é a discussão sobre o que seja a avaliação e suas diferentes manifestações.

Assim, vale destacar algumas concepções sobre avaliação:

É a atividade que consiste em fazer julgamento sobre uma intervenção, comparando os recursos empregados e sua organização (estrutura), os serviços e os bens produzidos (processo) e os resultados obtidos, com critérios e normas. (CONTANDRIOPOULOS et al, 1997, p. 37).

Em Aguilar e Ander-Egg (1994, p. 31), encontrase o seguinte entendimento:

A avaliação é uma forma de pesquisa social aplicada, sistemática, planejada e dirigida; destinada a identificar, obter e proporcionar de maneira válida e confiável dados e informação suficiente e relevante para apoiar um juízo sobre o mérito e o valor dos diferentes componentes de um programa (tanto na fase de diagnóstico, programação ou execução), ou de um conjunto de atividades específicas que se realizam, foram realizadas ou se realizarão, com propósito de produzir efeitos e resultados concretos; comprovando a extensão e o grau em que se deram essas conquistas, de forma tal que sirva de base ou de guia para uma tomada de decisões racional e inteligente entre cursos de ação, ou para solucionar problemas e promover conhecimento.
A contribuição de Silva e Brandão (2003) aponta para o seguinte:

Entendemos avaliação como a elaboração, a negociação, a aplicação de critérios explícitos de análise, em um exercício metodológico cuidadoso e preciso, com vistas a conhecer, medir, determinar e julgar o contexto, o mérito, o valor ou o estado de um determinado objeto, a fim de estimular e facilitar processos de aprendizagem e de desenvolvimento de pessoas e organizações.

São várias as concepções a respeito da avaliação. As contribuições escolhidas aqui visam esclarecer com maior segurança um entendimento sobre o que de fato consiste o que seja avaliação de políticas públicas. Nesta perspectiva, percebe-se então que uma boa avaliação visa a reduzir incertezas, a melhorar a efetividade das ações e a propiciar a tomada de decisões relevantes (MINAYO, 2010). Mais do que isso, deve apresentar uma relação dinâmica entre mundo objetivo e subjetivo. Isto é, concepções, valores, crenças que são referências numa dada realidade e que estarão presentes na tomada de decisões, nas ações concretas dos sujeitos.

A realização de qualquer programa ou serviço é um processo que possui movimento, uma dinâmica própria. Envolve a ação de sujeitos distintos que se aliam e se contrapõem. A avaliação, portanto, também busca compreender antagonismos e consensos que acontecem no cotidiano da execução dos programas/ serviços e que podem ser elementos favoráveis ou obstáculos à sua realização (DESLANDES, 2009).

Ainda mais, para Deslandes (2009)

A avaliação de programas sociais envolve sempre a perspectiva de mudança de uma situação, comportamentos ou problemas.

Outro aspecto imprescindível à avaliação é que na análise devem ser incluídas as percepções dos sujeitos sobre mudanças que ocorreram $e$ comparadas com aquelas que, a priori, eram esperadas pelos programas.

Portanto, corroborando com Silva (2008, p. 114), destaca-se

Que a pesquisa avaliativa assim percebida valoriza a análise crítica da política ou programa avaliado; busca os princípios e fundamentos teóricoconceituais da política ou programa; considera os sujeitos e interesses envolvidos no processo; fundamentase em valores e concepções sobre a realidade social partilhados pelos sujeitos da avaliação [...]; e contrapõe-se à ideia de neutralidade $[. .$.$] .$ 


\section{TIPOS DE AVALIAÇÃO}

A literatura sobre esse assunto é bastante vasta e aqui não se pretende esgotar uma temática de tamanha complexidade. Destacam-se apenas alguns tipos e modelos de avaliação, tendo em vista que se deterá com maior detalhe sobre a avaliação de impactos.

Cotta (2001, p. 91) considera que parte significativa dos estudos sobre os processos de avaliação de políticas públicas realizados desde a década de 1960, os quais, via de regra, tiveram (e ainda têm) o seu epicentro na academia norteamericana, refere-se às questões de ordem metodológica e/ou às distintas maneiras de se classificar a avaliação. A avaliação tem sido, usualmente, classificada em função do seu timing (antes, durante ou depois da implementação da política ou programa); da posição do avaliador em relação ao objeto avaliado (interna, externa ou semiindependente) e da natureza do objeto avaliado (contexto, insumos, processos e resultados).

Dessa forma, as avaliações podem ser classificadas segundo vários critérios. Considerando o agente que as realiza, as avaliações podem ser classificadas conforme Cohen e Franco (2004) e Cotta (1998) como:

Avaliação externa - realizada por pessoas de fora da instituição responsável pelo programa, em geral com experiência neste tipo de atividade. Entre as vantagens desta avaliação podem ser citadas a isenção e objetividade dos avaliadores externos, que não estão diretamente implicados com o processo, além da possibilidade de comparação dos resultados obtidos com os de outros programas similares já analisados. Por outro lado, o acesso aos dados necessários torna-se mais difícil e os que vão ter seu trabalho avaliado podem se colocar em posição defensiva, fornecendo informações parciais e minimizando o efeito de melhoria dos programas. Alega-se, também, que o conhecimento da metodologia de avaliação pode não substituir o conhecimento sobre as especificidades do programa, e que não existe uma única metodologia aplicável a todos os casos.

Avaliação interna - realizada dentro da instituição responsável, com maior colaboração das pessoas que participam do programa. Citam-se como vantagens a eliminação da resistência natural a um avaliador externo, a possibilidade de reflexão e aprendizagem e compreensão sobre a atividade realizada dentro da instituição. Mas pode-se perder muito em objetividade, já que os que julgam estão, também, envolvidos, tendo formulado e executado o programa. Se a avaliação for realizada internamente à instituição, mas por pessoas que não participam do programa, na tentativa de diminuir a subjetividade, a situação torna-se análoga à do avaliador externo.

Avaliação mista - procura combinar os tipos de avaliação anteriores, fazendo com que os avaliadores externos tenham contato estreito com os participantes do programa a ser avaliado, na tentativa de manter as vantagens e superar as desvantagens das avaliações apresentadas acima.

Avaliação participativa - $\quad$ usada principalmente para pequenos projetos, prevê a participação dos beneficiários das ações no planejamento, na programação, execução e avaliação dos mesmos.

Quanto à natureza, as avaliações podem ser:

Avaliações formativas - estão relacionadas à formação do programa. Adotadas durante a implementação, são voltadas para a análise e produção de informação sobre as etapas de implementação. Geram informações para os que estão diretamente envolvidos com o programa, com o objetivo de fornecer elementos para a realização de correções de procedimentos para melhorar o programa.

Avaliações somativas - estão relacionadas à análise e produção de informações sobre etapas posteriores. São realizadas quando o programa está sendo implementado há algum tempo ou após a sua implementação, para verificar a sua efetividade e fazer o julgamento do seu valor geral.

Quando se leva em conta o momento de sua realização, podem ser identificadas como (COHEN; FRANCO, 2004):

Avaliação ex-ante - realizada no começo de um programa, com o fito de dar suporte à decisão de implementar ou não o programa, e ordenar os vários projetos segundo sua eficiência para alcançar os objetivos determinados. O elemento central da avaliação ex-ante é o diagnóstico, que auxilia na alocação dos recursos disponíveis de acordo com os objetivos propostos. Para esta avaliação podem ser utilizadas as técnicas de Análise CustoBenefício e Análise Custo-Efetividade, mais afeita aos programas sociais.

Avaliação ex-post - realizada durante a execução de um programa ou ao seu final, quando as decisões são baseadas nos resultados alcançados. Neste tipo de avaliação julga-se, quando um programa está em execução, se ele deve continuar ou não, com base nos resultados obtidos até o momento e, se a resposta for positiva, deve-se manter a formulação original ou sofrer modificações. Quando o programa já foi concluído, julga-se a pertinência do uso futuro da experiência, ou seja, se o mesmo tipo de programa deve ser implementado novamente ou não. A avaliação ex-post é a mais desenvolvida metodologicamente e a que tem tido maior aplicação.

Tal diversidade de tipologias sobre avaliação deve ser compreendida com o propósito de promover uma articulação entre as mesmas, levando-se em consideração as características do programa a ser avaliado, o objeto, os critérios e os objetivos que pretende alcançar no decorrer da avaliação, além de 
outros requisitos indispensáveis à mesma (SILVA, 2008, p. 131).

De acordo ainda com Silva (2008, p. 147), os modelos de avaliação mais recorrentes na literatura se referem ao monitoramento, à avaliação política da política, à avaliação de processos e à avaliação de resultados e impactos.

No que se refere à avaliação política da política, Lima (2009) esclarece que a mesma

\begin{abstract}
Consiste em emitir um julgamento em relação à política em sua própria concepção e desenho; julga a pertinência do programa face a realidade que pretende modificar, bem como a coerência interna dos seus elementos constitutivos; consiste em analisar e elucidar os princípios de ordem política, econômica e sociocultural que fundamentam determinado modelo de intervenção social.
\end{abstract}

A autora acrescenta que a avaliação política da política tem como foco central a formulação da política ou planejamento do programa e tem como objetivo avaliar antecipadamente a potencialidade de sucesso de um programa.

Cabe, ainda que de maneira breve, sem aprofundamentos teóricos, já que não se trata do objetivo deste trabalho discutir tais modelos e sim centrar o foco na avaliação de impactos, apresentar, também, o conceito do que seja a avaliação de processo.

Dessa forma, a avaliação de processo

Consiste em avaliar em que medida o programa está sendo implementado conforme as diretrizes preestabelecidas; qual a relação entre o produto gerado e as metas previstas ou desejadas; se os meios utilizados estão adequados aos objetivos; qual a relação custobenefício. (LIMA, 2009, p. 82).

A avaliação de processo tem como foco central o funcionamento do programa e dos serviços prestados. E apresenta como objetivos: - identificar determinantes institucionais e socioculturais do sucesso ou fracasso da implementação; - oferecer sugestões e recomendações de procedimentos alternativos para corrigir distorções ou obstáculos na consecução das metas e objetivos.

\section{EM BUSCA DE REFERÊNCIAS CONCEITUAIS PARA ENTENDER A AVALIAÇÃO DE IMPACTO}

Conforme Roche (2002, p. 33), as primeiras abordagens sobre avaliação de impacto remontam à década de 1950, quando as agências de desenvolvimento dos Estados Unidos começaram a fazer uso dessa abordagem, numa tentativa de prever, antes do início de um projeto as prováveis consequências ambientais, sociais e econômicas do mesmo para aprová-lo, ajustá-lo ou rejeitá-lo.

Ainda Roche (2002, p. 37), numa tentativa de chegar a uma definição mais consistente para a avaliação de impacto, aponta que a

Avaliação de impacto é a análise sistemática das mudanças duradouras ou significativas - positivas ou negativas, planejadas ou não - nas vidas das pessoas e ocasionadas por determinada ação ou série de ações.

Nesse sentido, avaliação de impacto

Diz respeito aos efeitos do programa sobre a população-alvo e tem, subjacente, a intenção de estabelecer uma relação de causalidade entre a política e as alterações nas condições sociais. (DEUTSCHER, 1979; LIMA JR. et al, 1978; TULIOCK, 1978 apud FIGUEIREDO; FIGUEIREDO, 1986, p. 111).

Figueiredo e Figueiredo (1986, p. 115) esclarecem que a

Noção de causalidade embutida nas políticas com propósitos de mudança estabelece, ademais, que essas políticas são ações experimentais por excelência; são condições que visam alterar o futuro previsível dado pela inércia social.

Dentro deste mesmo ponto de vista, Lima (2009) adverte que a avaliação de impacto tem como objetivo estabelecer o grau de eficácia ou efetividade de um programa, identificando, tanto quanto possível, a relação de causalidade entre a variável independente (ações desenvolvidas) e a variável dependente (alterações nas condições sociais). E acrescenta: avaliação de impacto

Consiste em analisar até que ponto estão sendo alcançados os objetivos do programa, ou seja, os efeitos previstos ou desejados, além de considerar os efeitos imprevistos, positivos ou negativos, decorrentes das ações implementadas [tendo como foco] as mudanças quantitativas e qualitativas sobre as condições de vida de uma população atribuíveis ao programa.

Ao se referir ao critério a ser adotado em uma avaliação de impacto Figueiredo e Figueiredo 
(1986, p. 16) assinalam que a mesma tem por critério a aferição do sucesso/fracasso e efetividade, a qual, por decorrência da natureza do impacto pretendido, pode ser também objetiva, subjetiva e/ ou substantiva. E apontam, o critério da efetividade deve ser entendido como o grau em que a política é capaz de promover mudanças efetivas na realidade sobre a qual intervém.

Para Lima (2009), em conformidade com Figueiredo e Figueiredo (1986), a avaliação de impacto possui as seguintes dimensões:

a) impactos objetivos - mudanças quantitativas nas condições da população alvo - critério de aferição da mudança quantitativa entre o antes e o depois da execução do programa (efetividade objetiva);

b) impactos subjetivos - mudanças no estado de espírito da população - mudanças psicológicas, mudanças nos sistemas de crenças e valores (efetividade subjetiva);

c) impactos substantivos - mudanças qualitativas nas condições de vida da população (efetividade substantiva).

Dentre as abordagens mais comuns na avaliação de impacto, Howes, citado por Roche (2002, p. 33), destaca as seguintes: a avaliação de impacto ambiental, a avaliação de impacto social, análise de custo-benefício e análise de custobenefício social.

Para esta reflexão a respeito da avaliação de impacto, optou-se em discorrer sobre a avaliação de impacto social, tendo em vista que, segundo Roche (2002, p. 33),

Nos últimos anos, tem havido vários esforços para integrar as avaliações de impacto social e ambiental em formas mais coerentes.

Além disso, a contribuição de Muñiz (1997) sobre avaliação de impacto social é bastante elucidativa, se fazendo necessária apresentá-la para um entendimento mais aprofundado a respeito desta questão.

Dessa forma, Muñiz (1997) visa esclarecer primordialmente o conceito de impacto social, atribuindo o valor do humano diante da crise e do ajuste estrutural. Assim, aparece a necessidade de entender e praticar a avaliação como uma atitude diante da vida e das coisas. A mesma autora considera que se trata de uma perspectiva diferente para interpretar as possibilidades e as limitações do desenvolvimento, que permita avançar na tarefa de construir o futuro.

A autora adverte que, como resposta à crise econômica, os governos dos países da América Latina e do Caribe, têm tido a tarefa de pôr em prática políticas de estabilização e programas de ajuste estrutural, orientados a restaurar os desequilíbrios macroeconômicos, alicerçados em uma drástica contração da demanda interna, tanto com o objetivo de reduzir os incentivos reais como com o gasto público, em particular, com o gasto social (MUÑIZ, 1997, p. 3).

Tais medidas são aplicadas ao custo de um impacto social negativo nas condições de vida da população, particularmente nos setores mais vulneráveis. Sem dúvida, na medida em que os processos de produção e reprodução do capital se tornam mais complexos e, de acordo com o desenvolvimento específico de cada país, se consubstanciam com maior nitidez as desigualdades sociais (MUÑIZ, 1997, p. 3).

O processo de acumulação, concentração e centralização do capital e sua posterior transnacionalização; os laços financeiros estabelecidos através de investimentos e empréstimos; assim como o intercâmbio comercial realizado em termos desfavoráveis para os países periféricos, entre outros fatores, aprofundam mais ainda as desigualdades sociais. Isto se expressa, fundamentalmente em uma crescente deterioração do nível de qualidade de vida de grande parte da população (MUÑIZ, 1997, p. 16).

É nesse contexto que a autora aborda a avaliação de impacto como uma perspectiva teóricometodológica para avaliar políticas, programas e projetos (sociais ou não) e não como um simples critério de avaliação ex-post.

Para a autora, então, o impacto social é de difícil definição, pela quantidade de elementos interrelacionados que estão presentes no significado de impacto. Mesmo assim, ela o define como sendo as mudanças ou variações desejadas aos destinatários das políticas (sociais ou não), programas e projetos relativas a:

a) satisfazer as necessidades básicas ou não básicas;

b) promover ou procurar condições para a melhoria das condições de vida e de trabalho;

c) gerar, fortalecer ou consolidar níveis e instâncias organizativas, formas de expressão, associação e participação organizada;

d) proporcionar mudanças de atitudes, condicionantes, aptidões, comportamentos e mentalidades que modifiquem as concepções e atuações dos sujeitos sociais, dos quais os indivíduos e grupos fazem parte. (MUÑIZ, 1997, p. 73).

Neste sentido, o conceito de impacto social se refere:

a) às mudanças ou variações no nível e grau de estruturação formal, das respostas 
institucionais orientadas a alcançar um impacto social buscado;

b) aos efeitos desejados no contexto social (econômico, político, cultural, tecnológico, ecológico etc.) em que se inscrevem as políticas, programas e projetos, e que se refletem em mudanças ou variações nas variáveis demográficas, sociais, econômicas, culturais, tecnológicas, ecológicas etc. que podem ser imputáveis na presença daqueles. (MUÑIZ, 1997, p. 74).

De modo que, o impacto social assim concebido, pode ser observado em três níveis básicos:

a) nos destinatários das ações avaliadas;

b) no meio institucional no qual se formulam, promovem, desenvolvem, executam e avaliam as ações consideradas na avaliação;

c) no contexto no qual se inscrevem as ações avaliadas e os sujeitos sociais que as respaldam. (MUÑIZ, 1997, p. 74).

Observado tais critérios, definir impacto social então necessita redefinir o conteúdo do social, levando em consideração o conceito de totalidade social, ou seja, o impacto social está indubitavelmente ligado a uma concepção de totalidade social, que se refere à "[...] realidade como um todo estruturado e dialético no qual pode ser conhecido qualquer fato." (KOSIK, 1976, p. 45).

Assim, o social aparece como uma perspectiva de interpretação da realidade, compreendendo o político e o econômico (sem possibilidade de compartimentalizar a clássica divisão em: o econômico, o social, o político etc.). Enfim, o impacto é social porque impacta a sociedade genericamente falando e, como a sociedade se constitui de indivíduos e grupos, em particular o impacto é social porque afeta os grupos humanos.

Do ponto de vista de sua função éticofilosófica, a expressão válida do impacto social é a satisfação das necessidades básicas e não básicas e como isto incide na melhoria da situação, condição e qualidade de vida. Ter acesso a um emprego digno com remuneração adequada e de acordo com os níveis de classificação dos indivíduos, participar nos processos organizativos que conduzem à tomada de decisões, ter acesso a ampliação de conhecimentos, ao desenvolvimento de habilidades e competências, são entre outros, os impactos que se devem buscar através de qualquer política, programa ou projeto. Ou, ao menos, a criação de condições que favoreçam alcançar tais propósitos (MUÑIZ, 1997).

A questão central, então, consiste em considerar o impacto social não somente como um critério de avaliação, mas sim como um enfoque particular para a avaliação (MUÑIZ, 1997, p. 76).

$\mathrm{Na}$ literatura existente, normalmente o conceito de impacto, principalmente no momento em que as políticas econômicas tendem a restringir os gastos sociais e a privilegiar a prestação de serviços sociais nas mãos de empresas privadas, uma das mais marcantes características do neoliberalismo ocorrido em vários países, durante as décadas de 70/80 e no Brasil iniciado em 90, a consideração da medida de impacto aparece como uma espécie de modismo que conquista os políticos e as instituições nacionais e organismos internacionais.

Tal interesse pelo impacto social, tem se traduzido como um critério a mais de avaliação. Percepção parcial e incompleta, na medida em que o impacto social deve ser considerado como uma perspectiva de interpretação para a avaliação, que define sua especificidade ao intentar medir mudanças "situacionais" de importância que marcam um acercamento significativo ao alcance da imagem-objetivo, validando assim, uma determinada trajetória de ação (MUÑIZ, 1997, p. 77).

Assim, avaliar impacto social não pode se limitar ao cálculo de indicadores que dão conta da rentabilidade da inversão, ou estabelecer o custobenefício ou custo-eficiência considerados no início do projeto, ou ainda, a comparar o programado versus o executado, no marco do controle de uso do tempo ou dos recursos financeiros préestabelecidos. O ponto-chave então é que a rentabilidade e a eficiência são consideradas como critério de análise e não como único elemento para a tomada de decisões (MUÑIZ, 1997, p. 78).

A avaliação de impacto social é também uma perspectiva que recupera outros aspectos interessantes de outros enfoques, interpretados com uma lógica de racionalidade distinta e contextualizada no marco de outros critérios para a tomada de decisão (MUÑIZ, 1997, p. 78).

Segundo a autora, existem a respeito da avaliação de impacto social algumas falsas interpretações, quais sejam: situar a avaliação de impacto social como uma perspectiva que só se ocupa de aspectos sociais, sem valorizar outros elementos; conceber o impacto social somente como um critério de avaliação ex-post (não é necessário que se finalize a execução de uma ação para avaliar seu impacto social).

O impacto social não é exclusivamente um critério de avaliação, mas sim um enfoque metodológico para tal fim. Independente da fase ou etapa em que se encontra a intervenção, o enfoque da avaliação do impacto social pode ser aplicado. Em todos os casos (ex-ante ou ex-post) o que interessa é determinar até que ponto as medidas avaliadas são as responsáveis do impacto social observado (MUÑIZ, 1997, p. 79). 
Em relação à medida do impacto social, a autora esclarece: o problema fundamental para a medição do impacto social é que as mudanças que se quer medir geralmente estão associadas com a qualidade. Como medir algo tão abstrato como a qualidade? Se qualidade pode ser entendida como o cumprimento dos requisitos, então ela deixa de ser uma medida subjetiva de gosto e preferências pessoais e se converte em um conceito susceptível de ser medido objetivamente (MUÑIZ, 1997, p. 86).

Operar a medição da qualidade é avaliar os processos desenvolvidos, para determinar até que ponto estes cumprem, ou não, com os requisitos dos usuários ou destinatários finais.

Para isso, a autora apresenta quatro perguntas chaves que vão orientar todo o processo de medição do impacto social:

a) Quem são os destinatários (diretos, indiretos, intermediários e finais) das ações avaliadas?

b) Quais são os interesses e expectativas dos destinatários de tais ações?

c) Quais são os resultados esperados das ações avaliadas?

d) Quais são os requisitos que devem ser atingidos pelos resultados? (MUÑIZ, 1997, p. 87).

O que vai implicar na medição da qualidade é a identificação dos fatos observáveis relacionados com a produção da qualidade. De tal maneira que envolva:

a) A análise ou exame do ambiente que significa, fundamentalmente, identificar, caracterizar e classificar os sujeitos sociais e seu grau de compromisso com a geração do impacto social;

b) A análise ou exame das estruturas que respaldam os processos de geração do impacto social;

c) A análise ou exame dos processos mesmos de geração do impacto social;

d) A análise ou exame dos resultados.

Enfim, o impacto social é uma função éticofilosófica, ligada a uma determinada concepção de mundo que resgata os valores do ser humano, seu desenvolvimento, sua criatividade, no contexto de um processo de aprendizagem guiado e direcionado para formas de convivência superior (MUÑIZ, 1997, p. 88).

\section{CONCLUSÃO}

A discussão teórica aqui apresentada buscou contemplar os diferentes tipos de avaliações e conceitos relacionados à avaliação de políticas públicas. Entretanto, espera-se que a ênfase dada à avaliação de impacto deva ser destacada como uma relevante contribuição acerca deste assunto.

Numa tentativa de situar a avaliação de impacto, tornou-se necessário entender a avaliação como um movimento no processo dinâmico das políticas públicas, as suas diversas e complementares concepções e os seus variados tipos e modelos de avaliação.

A avaliação do impacto social pelo seu recente desenvolvimento; pelas limitações inerentes à sua própria natureza; pela deficiente abordagem metodológica para a construção de um objeto de avaliação e sua operacionalização em uma estratégia que lhe dê tratamento metodológico; pela escassa e restrita difusão das experiências de trabalho nesse sentido, entre outras questões, apresenta uma série de deficiências que devem ser enfrentadas para sua aplicação coerente e científica.

Tais desafios merecem especial atenção para o desenvolvimento de uma cultura avaliativa, que defenda, entenda e internalize a avaliação antes de tudo como uma atitude diante da vida e das coisas e como um instrumento para construir o futuro (MUÑIZ, 1997, p. 83).

Não pretendemos encerrar tais reflexões neste esboço de compreensão da temática aqui apresentada. $\mathrm{Na}$ verdade, torna-se necessário suscitar novas discussões e aprofundá-las dentro de uma visão mais crítica, num esforço de aprofundamento teórico e de contribuição para os estudos desenvolvidos no campo das políticas públicas, notadamente, sobre a avaliação de impacto.

\section{REFERÊNCIAS}

AGUILAR, Maria José; ANDER-EGG, Ezequiel. Avaliação de serviços e programas sociais. 2. ed. Petrópolis: Vozes, 1994.

COHEN, Ernesto; FRANCO, Rolando. Avaliação de projetos sociais. Petrópolis: Vozes, 2004.

CONTANDRIOPOULOS, André Pierre et al. A avaliação na área da saúde: conceitos e métodos. In: HARTZ, Z. M. A. Avaliação em saúde: dos modelos à prática na análise da implantação de programas. Rio de Janeiro: FIOCRUZ, 1977. p. 29-48.

COTTA, Tereza C. Avaliação educacional e políticas públicas: a experiência do Sistema Nacional de Avaliação da Educação Básica (SAEB). Revista do Serviço Público, Brasília,v. 52, n. 4, p. 89-111, 2001.

Metodologias de avaliação de programas e projetos sociais: análise de resultados e de impacto. Brasília, Revista do Serviço Público, Brasília, ano 49, n. 2, abr./jun., 1998. 
FARIA, Carlos Aurélio Pimenta. A política da avaliação de políticas públicas. Revista Brasileira de Ciências Sociais, São Paulo, v. 20, n. 59, p.114 , out. 2005.

FIGUEIREDO, Marcus Faria; FIGUEIREDO, Argelina Maria Cheibub. Avaliação política e avaliação de políticas: um quadro de referência teórica. Análise a Conjuntura, Belo Horizonte, v. 1, n. 3, p. 107-127, set./dez. 1986.

HOFLING, Eloisa de Mattos. Estado e políticas (públicas) sociais. Cadernos CEDES, Campinas, v. 21, n. 55, nov. 2001.

KOSIK, K. Dialética do concreto. Rio de Janeiro: Paz e Terra, 1976.

LIMA, Valéria Almada. Reforma do Estado e controle social: limites e possibilidades da descentralização e do "terceiro setor". Revista de Políticas Públicas, São Luís, v.6, n. 2, p. 127-147, jan./jun. 2002.

Qualificação e emprego: uma avaliação de impactos do PLANFOR no Maranhão. In: SILVA, Maria Ozanira da Silva e (Coord.). Pesquisa avaliativa: aspectos teórico-metodológicos. São Paulo: Veras Editora, 2008.

Modelos clássicos de avaliação de políticas e programas sociais. São Luís, 2009. Aula ministrada na disciplina Metodologia de Avaliação de Políticas e Programas Sociais do Programa de PósGraduação em Políticas Públicas da Universidade Federal do Maranhão.

MÉSZÁROS, István. Para além do capital: rumo a uma teoria da transição. Campinas: Boitempo, 2009.

MONTAÑO, Carlos. Terceiro setor e questão social: crítica ao padrão emergente de intervenção social. 4. ed. São Paulo: Cortez, 2007.

MUÑIZ, Arlette Pichardo. Evaluación del impacto social: el valor de lo humano ante la crisis y el ajuste. Buenos Aires: Lumen-Hvmanitas, 1997.

ROCHE, Chris. Avaliação de impacto dos trabalhos de ONGs: aprendendo a valorizar as mudanças. 2. ed. São Paulo: Cortez, 2002.

RUA, Maria das Graças. Análise de políticas públicas: conceitos básicos. [19--] (Mimeo.)

SILVA, Maria Ozanira da Silva e. Avaliação de políticas e programas sociais: uma reflexão sobre o conteúdo teórico e metodológico da pesquisa avaliativa. In: SILVA, Maria Ozanira da Silva e (Coord.). Pesquisa avaliativa: aspectos teóricometodológicos. São Paulo: Veras Editora, 2008.
SILVA, R.R.; BRANDÃO, D.B. Os quatro elementos da avaliação. Olho Mágico, Londrina, v. 10, n. 2, p. 59-66, abr./jun. 2003.

SOUZA, Celina. Políticas públicas: uma revisão da literatura. Sociologias, Porto Alegre, ano 8, n. 16, p. 20-45, jul/dez. 2006.

\section{Maria da Glória Serra Pinto de Alencar Bibliotecária \\ Doutoranda do Programa de Pós-Graduação em Políticas Públicas da Universidade Federal do Maranhão (UFMA) Professora Adjunta da Universidade Federal do Maranhão (UFMA) \\ E-mail: glorinha500@hotmail.com}

Universidade Federal do Maranhão (UFMA)

Cidade Universitária, Av. dos Portugueses, 1966, Bacanga

- São Luís/MA

CEP: 65080-805 